\title{
Antixenotic Resistance of Cabbage to Onion Thrips (Thysanoptera: Thripidae). I. Light Reflectance
}

\author{
JÓZSEF FAIL, ${ }^{1,2}$ MARK E. DEUTSCHLANDER, ${ }^{3}$ AND ANTHONY M. SHELTON ${ }^{4}$
}

\begin{abstract}
J. Econ. Entomol. 106(6): 2602-2612 (2013); DOI: http://dx.doi.org/10.1603/EC13232
ABSTRACT Onion thrips (Thrips tabaci Lindeman) has become a significant pest of cabbage (Brasssica oleracea $\mathrm{L}$.) in regions with a dry continental climate. Thrips-resistant cabbage varieties have been developed in breeding programs, but the mechanisms of resistance remain largely unknown. Antixenosis, one of the three resistance mechanisms, may play a role but no plant trait has been identified as a source of antixenosis. A series of studies were conducted to identify resistance mechanisms in this insect-crop interaction and to seek plant traits that were correlated to resistance. In this first article of the series, the result of studying antixenosis and overall resistance of cabbage and the correlation between antixenosis and light reflectance characteristics are reported. There were distinct differences in the overall resistance to thrips between the six cabbage varieties studied. There were more pronounced differences between varieties based on the number of damaged head leaves compared with the use of damage ratings as a measure of overall resistance. Varieties also differed in their level of antixenosis; proportional abundance of thrips adults on head-forming leaves was more closely correlated to overall resistance of cabbage than actual thrips numbers. Some of the variables computed from the recorded reflectance spectra of cabbage were correlated to thrips abundance on head-forming leaves only in the first but not in the second year of this study, suggesting that either spectral characteristics do not affect antixenosis or other variables may affect thrips' responses to spectral cues. Furthermore, multiple spray applications of a kaolin particle-based product significantly changed the light reflectance characteristics of cabbage, but it did not reduce the actual thrips abundance on head-forming leaves.
\end{abstract}

KEY WORDS Thrips tabaci, Brassica oleracea, resistance, antixenosis, light reflectance

In the past three decades, onion thrips, Thrips tabaci Lindeman 1889 (Thysanoptera: Thripidae), has become a significant pest of white cabbage (Brasssica oleracea L. convar. capitata (L.) Alef. variety alba D.C.), mainly in regions with a dry continental climate. New York State entomologist J.A. Lintner (1892) first noted the scarring damage to cabbage by T. tabaci, which results in whitish or silvery appearance of outer leaves. The damage on head-forming leaves, however, has a different appearance; sometimes referred to as russeting, the leaf surface becomes bronze or rust colored with a rough texture (Sirrine and Lowe 1894). Although its damage on cabbage had been known for more than a century, T. tabaci was not considered an important cabbage pest until the 1980s. Since then it has become a significant pest in several regions of the world, and prevention of damage has primarily focused on host plant resistance and use of insecticides (Shelton et al. 1998). Because the man-

\footnotetext{
${ }^{1}$ Department of Entomology, Corvinus University of Budapest, 29-43 Villányi út, Budapest, 1118, Hungary.

22Corresponding author, e-mail: jozsef.fail@uni-corvinus.hu.

${ }^{3}$ Department of Biology, Hobart and William Smith Colleges, 300 Pulteney St., Geneva, NY 14456

${ }^{4}$ Department of Entomology, Cornell University/NYSAES, 630 West North St., Geneva, NY 14456.
}

agement of thrips in cabbage by using insecticides is an expensive approach, it has been suggested that breeders increase efforts to produce thrips-resistant cabbage varieties (Shelton et al. 2008).

Three fundamental mechanisms of plant resistance to insects are nonpreference, antibiosis, and tolerance (Painter 1951). Painter defined nonpreference as "the group of plant characters and insect responses that lead away from the use of a particular plant or variety, for oviposition, for food, or for shelter, or for combinations of the three." Nonpreference has been replaced by the term antixenosis (Kogan and Ortman 1978). Antibiosis is defined "for those adverse effects on the insect life history which result when the insect uses a resistant host-plant variety or species for food" (Painter 1951). "Tolerance is a basis of resistance in which the plant shows an ability to grow and reproduce itself or to repair injury to a marked degree in spite of supporting a population approximately equal to that damaging a susceptible host" (Painter 1951).

Despite studies by several investigators, the resistance mechanism(s) of cabbage to T. tabaci remain unknown (Shelton et al. 2008). Within-plant distributions of T. tabaci on cabbage have been found to vary with susceptibility or resistance; on susceptible cabbage varieties, preference was observed toward head- 
forming leaves over frame leaves, whereas the opposite distribution was found on resistant varieties (North and Shelton 1986; Stoner and Shelton 1988a,b). There was very little difference between susceptible and resistant varieties in the total number of thrips on whole plants, suggesting that whole plant resistance may be best described as tolerance (Stoner and Shelton 1988b). However, Stoner and Shelton (1988b) suggested that the observed reduction in thrips damage on resistant cabbages is, at least in part, the result of reduced thrips numbers in the head because of antixenosis.

The probability of colonizing thrips remaining in the head of a plant was found independent of the attractiveness of the frame leaves of the same plant (Stoner and Shelton 1988a). The observed preference among heads of different varieties could have been the result of more rapid take-off after landing on the head of a resistant variety, rather than choosing landing sites among the heads of the available plants. The long distance orientation and short-range movement of thrips between neighboring plants are not well understood, so it is difficult to determine to what extent they are choosing among plants or plant parts in an array (Stoner and Shelton 1988a). Whether T. tabaci are able to choose between head and outer leaves for landing or it is their postalighting nonpreference for head leaves of resistant varieties, the resistance mechanism resulting in the observed within-plant distributional difference appears to more closely fit antixenosis. Based on differences in the number of colonizing T. tabaci adults collected in cabbage heads only, it appears that some of the studied cabbage varieties possess antixenotic resistance to $T$. tabaci (Fail et al. 2008). To date, no other resistance mechanism has been identified that could result in less thrips damage on head-forming leaves of white cabbage.

To our knowledge, no plant trait has been identified as a source of antixenotic resistance in cabbage to $T$. tabaci. Although in field tests the number of T. tabaci collected from head leaves of susceptible and resistant cabbage plants was significantly different, in a laboratory free-choice array using leaf disks of the same cabbage varieties, T. tabaci showed no preference for any of the varieties. Therefore, thrips may prefer susceptible heads on the basis of some characteristic not present in leaf disks (Stoner and Shelton 1988a). Because the brightness of white cabbage outer head leaves was negatively correlated to the number of adult $T$. tabaci found inside the head in an early stage of head formation, Fail et al. (2008) proposed that the reflectance of cabbage leaves both in the visual and ultraviolet (UV) range of light might also be correlated to antixenotic resistance of cabbage.

Like other insects, thrips locate hosts by using color, shape, size, and volatiles. Color and color contrast are used by some thrips species to distinguish between a host and the surrounding environment (Terry 1997). The critical components of color for discriminating between hosts and nonhosts are hue (the dominant wavelength reflected by the surface, $\left.\lambda_{\max }\right)$ saturation (or purity of the hue), and brightness (the total energy or percentage reflectance at peak wavelengths). To determine which color qualities are most attractive to thrips, researchers have tested painted surfaces of traps and evaluated the number trapped on different colors. Such data only indicate those characters that affect thrips alighting on a host and do not give information on the residence time or subsequent leaving rates (Terry 1997). Behavioral studies of the color preference of $T$. tabaci have provided variable results, but generally agree that greater numbers of thrips are caught by low UV-reflective white, blue, and yellow traps than are caught by green, red, black, and high UV-reflective white traps (Kirk 1984, Czencz 1987, Lu 1990, Teulon and Penman 1992, Trdan 1999, Szénási et al. 2001, Natwick et al. 2007).

Although the spectral sensitivity of T. tabaci photoreceptors remains unknown, the results of the aforementioned behavioral studies strongly suggest that $T$. tabaci vision should cover the general insect-visible spectrum, roughly between 350 and $650 \mathrm{~nm}$ (Menzel 1979). More information is available about the spectral sensitivity of two other thrips species. Behavioral responses of western flower thrips (Frankliniella occidentalis Pergande 1895) to colored traps suggest that it has a visual system with three photoreceptors with peak sensitivity in UV $\left(\lambda_{\max }: 350-360 \mathrm{~nm}\right)$, blue $\left(\lambda_{\max }\right.$ : $440-450 \mathrm{~nm}$ ), and yellow ( $\left.\lambda_{\text {max }}: 540-570 \mathrm{~nm}\right)$ wavelengths (Vernon and Gillespie 1990). Physiological evidence from electroretinograms of $F$. occidentalis confirmed UV-A (315-400 nm) sensitivity and a yellow photoreceptor but found no evidence for a blue photoreceptor (Matteson et al. 1992); the spectral sensitivity curve was determined in the human visible region but only a single wavelength (365 nm) was tested in the UV-A region, thus information about the shape of the sensitivity curve is lacking. Interestingly, behavioral responses of American bean thrips (Caliothrips phaseoli Hood 1912) have shown they are capable of detecting UV-B (280-315 nm) wavelengths (Mazza et al. 2002), likely because of UV-A-induced fluorescence of some of the ommatidia in the compound eye (Mazza et al. 2010). Thus, UV-B vision in this species appears to be achieved by a standard UV-A photoreceptor $\left(\lambda_{\max }=360 \mathrm{~nm}\right)$ and a sharp cut-off internal filter that blocks longer UV wavelengths in the majority of the ommatidia.

We continue to investigate resistance mechanism(s) of cabbage that play a role in its interaction with T. tabaci and to seek plant traits that are correlated to resistance. In this first paper, we report the result of measuring antixenotic and overall resistance of white cabbage varieties under pressure from $T$. tabaci populations and the correlation between antixenotic resistance and light reflectance characteristics of the studied varieties.

\section{Materials and Methods}

Plant Material. Six white cabbage hybrids were used in this study: 'Balashi' $\mathrm{F}_{1}$ (Bakker Brothers, Noord-Scharwoude, Holland), 'Bloktor' $F_{1}$ and 'Quisor’ $F_{1}$ (Syngenta Seeds Inc., Enkhuizen, Holland), 


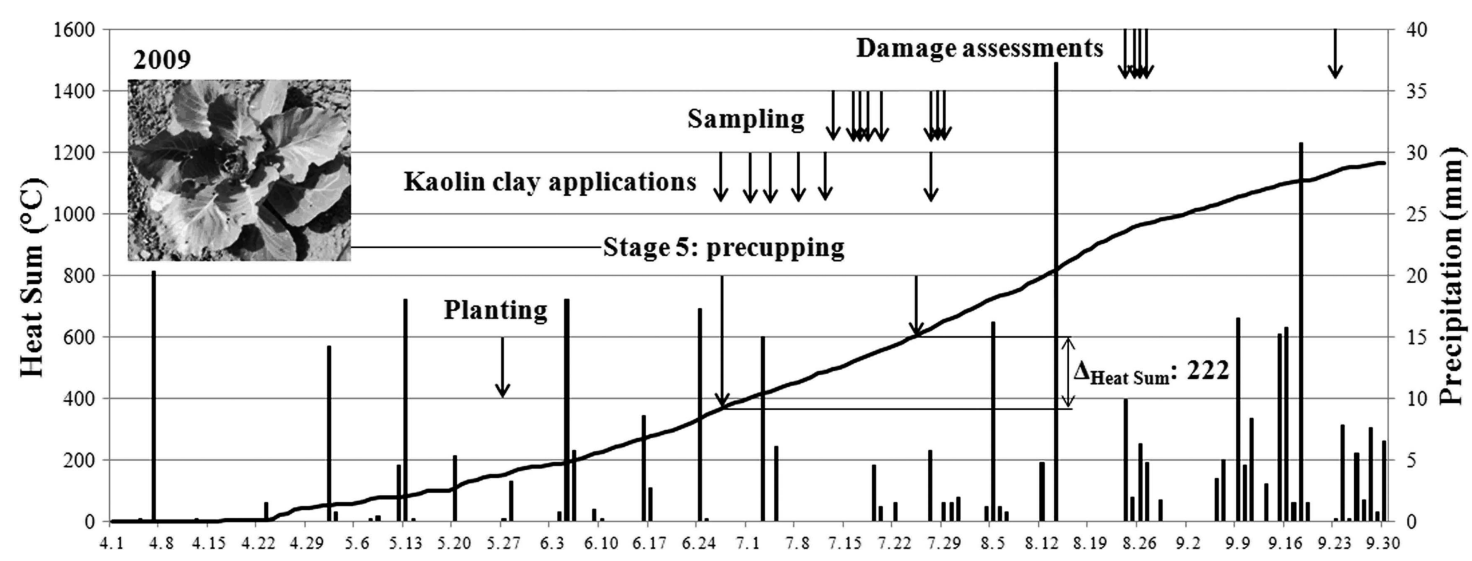

Fig. 1. Cumulated effective temperature for the development of T. tabaci and precipitation recorded in 2009.

'Green Gem’ $F_{1}$ (Hungnong International Co. Ltd., Seoul, Korea), 'Hurricane’ F ${ }_{1}$ (Bejo Zaden B.V., Warmenhuizen, Holland), and 'Riana' $F_{1}$ (Daehnfeldt A/S, Odense, Denmark). The overall resistance of these cabbage hybrids to $T$. tabaci has previously been studied in Hungary (Fail 2006, Fail et al. 2008). According to these studies, Balashi and Riana were highly resistant, Green Gem and Hurricane were highly susceptible, and Bloktor and Quisor were categorized as moderately resistant and susceptible, respectively.

Plants were seeded into 128-cell 4.5-cm-deep Styrofoam seed starter trays with one seed per cell filled with Cornell mix soil (Boodley and Sheldrake 1972), and then grown under greenhouse conditions at 10$25^{\circ} \mathrm{C}$ and $40-80 \% \mathrm{RH}$ with supplemental lights set for a photoperiod of 14:10 (L:D) h. Cabbage seedlings (6 wk old) were transplanted to field plots at the research farm of the New York State Agricultural Experiment Station, Geneva, NY (42.873621, -77.029556), on 27 May 2009 and 2 June 2011. Transplants were arranged in a randomized complete block design consisting of six blocks, each block with 90 plants of a given variety. Plant spacing was 0.76 by $0.46 \mathrm{~m}$. Treflan EC (2.3 liter/ha) was applied $2 \mathrm{~d}$ before planting and Dual II Magnum (1.2 liter/ha) $2 \mathrm{~d}$ after planting for managing weeds. No other pesticides were applied. In 2011, plants were irrigated four times $(25 \mathrm{~mm}$ each occasion). Three plots of each variety were sprayed with kaolin clay (Surround WP: $56 \mathrm{~kg} / \mathrm{ha}$ ) complemented with a surfactant (Silwett L-77: 0.1\%) and the other three plots served as untreated controls. Surround WP was first applied on 27 June and 26 June in 2009 and 2011, respectively. After significant rainfalls or overhead irrigations, kaolin clay was reapplied in the same manner as described earlier five and seven times in 2009 and 2011, respectively (Fig. 1 and 2).

Sampling Procedure. Cabbage transplants entered the fifth growth stage precupping (Andaloro et al. 1983) around 27 June and 10 July in 2009 and 2011, respectively (Fig. 1 and 2). From this growth stage onward, thrips may become protected in the heart leaves of the plant, thus this event likely indicates the possible beginning of T. tabaci colonizing head leaves of cabbage.

Sampling at Early Head Formation. In 2009, 16 small cabbage heads per plot were collected and placed individually into a prelabeled zip-lock plastic bag. This resulted in 48 replicates per treatment. At the same time, one of the outer head leaves was removed from the small head and placed into a separate zip-lock

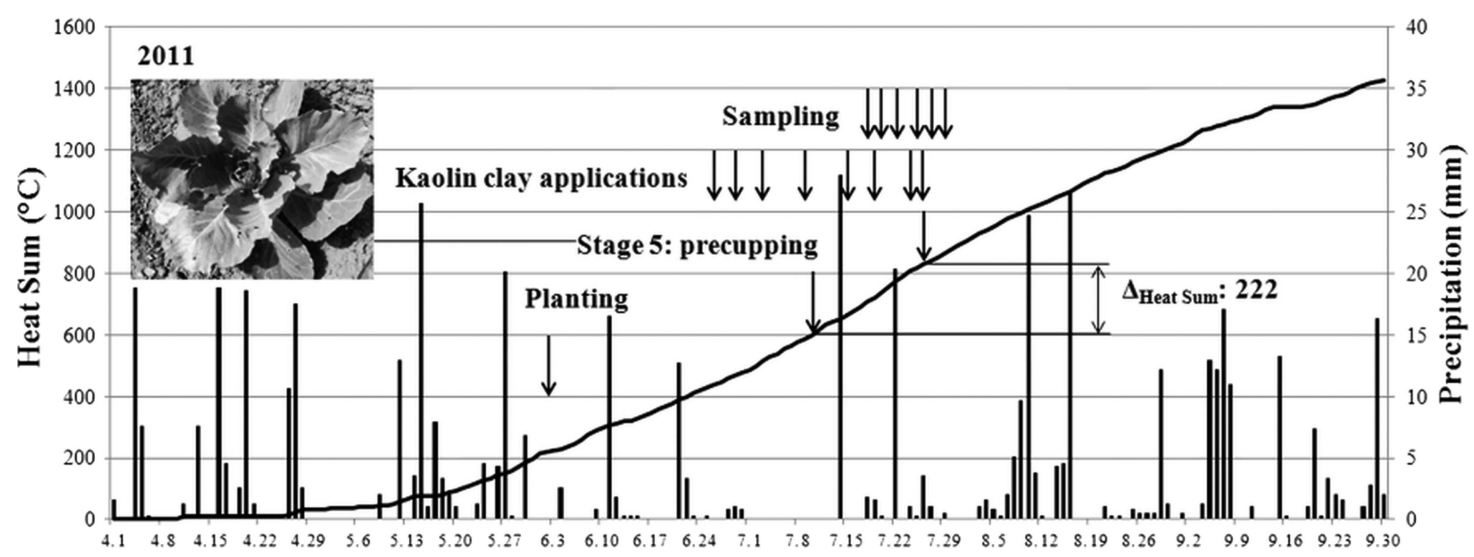

Fig. 2. Cumulated effective temperature for the development of T. tabaci and precipitation recorded in 2011. 
plastic bag with a label matching the label of the bag containing the head from where it was removed. The position of sampled plants within a plot was recorded. The cabbage heads were kept in a cooler room at $4^{\circ} \mathrm{C}$ until their weight was measured, immediately followed by counting the T. tabaci adults on head leaves under a dissecting microscope. The relative proportion of T. tabaci (expressed as integer percent values) on each variety as a function of the total number of $T$. tabaci collected across all six varieties was computed. The actual count and the proportional abundance of T. tabaci adults were both used to express antixenotic resistance of cabbage varieties.

The reflectance spectrum (see later) of the single head leaf removed from each sampled cabbage head was recorded within a few hours. Kaolin clay-treated and untreated control plots of a given variety were sampled on the same day, but because of the large number of samples, the six cabbage varieties were sampled on three different days: Green Gem and Quisor on 13 July, Balashi and Riana on 16 July, and Hurricane and Bloktor on 17 July (dates marked by vertical downward arrows on Fig. 1).

Based on published data about the effect of temperature on the development of T. tabaci (Edelson and Magaro 1988, Shevchenko and Popov 1989, van Rijn et al. 1995, Murai 2000), a degree-day (DD) model was computed for both 2009 and 2011. A single developmental zero temperature $\left(10.3^{\circ} \mathrm{C}\right)$ and a thermal constant (222 DD) for total development (from egg to adult emergence) were calculated. Temperature and precipitation were recorded at a weather station in proximity to the trial site (within $500 \mathrm{~m}$ ) and the daily mean temperature was calculated from these data. The first $3 \mathrm{~d}$ of sampling (collecting cabbage heads) were timed to be well within the calculated 222 DD limit from the beginning of the precupping growth stage (Fig. 1).

A single old leaf was collected and placed individually into a prelabeled plastic bag from every previously sampled plant of each variety on five separate occasions: Green Gem on 18 July, Quisor on 20 July, Balashi on 27 July, Riana on 28 July, and Hurricane and Bloktor on 29 July (dates marked by vertical downward arrows on Fig. 1). The reflectance spectrum of these old leaves was also recorded within a few hours.

In 2011, the sampling procedure described earlier was repeated with one notable difference. Three small cabbage heads per plot were collected from every cabbage variety in both kaolin clay-treated and untreated control blocks on a given sampling day. At the same time, an outer head-forming leaf and an old leaf were also collected from every sampled plant and their reflectance spectra were recorded within a few hours. There were six sampling events within 2 wk: 18, 20, 22 , 25,27 , and 29 July (dates marked by vertical downward arrows on Fig. 2). This resulted in 54 replicates per treatment for the six sampling events combined.

Sampling at Harvest Maturity. Thrips damage was assessed only in 2009 on the same day for kaolin claytreated and untreated control at harvest maturity of the given variety: Green Gem on 24 August, Balashi on
25 August, Riana on 26 August, Quisor on 27 August, Hurricane and Bloktor on 23 September (dates marked by vertical downward arrows on Fig. 1). Sixteen cabbage heads per plot were collected and their weights were recorded individually. Thrips damage was assessed on a leaf-by-leaf basis and only on the lower side of a given leaf (the outer side of a headforming leaf) before the leaf was removed and the next one was examined. Repeating this procedure, one leaf was assessed after another until four consecutive leaves had no damage symptoms. The extent of thrips damage was noted for each head-forming leaf in the form of the proportion of damaged surface to the entire surface of the leaf rounded to the closest decimal and resulting in decimal values between zero and one. The sum of these decimals and the number of damaged leaves within a cabbage head were subject to statistical analysis.

Reflectance Spectrophotometry. The reflectance spectra of the leaves were recorded by using a USB2000 spectrophotometer, with an internal chargecoupled device and diffraction grating capable of UV detection, and a PX-2 pulsed Xenon light source (Ocean Optics, Dunedin, FL). The spectrophotometer and the lamp were connected through a bifurcated fiber optic (Ocean Optics R200-7-UV/VIS), fitted at the common end with a copper cylinder to standardize measuring distance $(\approx 5 \mathrm{~mm})$ and spot size $(\approx 7 \mathrm{~mm})$ and to eliminate ambient light. The probe was oriented perpendicular to the leaf surface. Three readings were taken on every leaf on upper surface areas, where the leaf cuticle was intact, resulting in 144 and 162 readings per treatment in 2009 and 2011, respectively. Each individual reading was the result of averaging 20, 10-msec-duration flashes from the pulsed xenon lamp. Reflectance was corrected for dark noise of the charge-coupled device detector and was calculated relative to a WS-2 white standard by using Ocean Optics, Inc., Base32 operating software and the following equation:

$\%$ Reflectance $\lambda=[(\mathrm{S} \lambda-\mathrm{D} \lambda) /(\mathrm{R} \lambda-\mathrm{D} \lambda)] \times 100 \%$

where $\mathrm{S} \lambda$ is the intensity of the particular wavelength $\lambda, \mathrm{D} \lambda$ is the dark intensity at wavelength $\lambda$, and $\mathrm{R} \lambda$ is the reference intensity at wavelength $\lambda$ (Ocean Optics Inc. 2003).

Although spectral reflectance was measured every one-third of a nanometer from $170 \mathrm{~nm}$ to $880 \mathrm{~nm}$, a more limited spectral range based on the likely visual sensitivity of T. tabaci was used in our analyses (see computed spectral variable 1 in this paragraph). Raw spectra were imported into a spreadsheet program, and then smoothed by rounding the wavelength values to integers and calculating the mean of the recorded values for every nanometer in the recording range. Then an average spectrum was computed from the three recorded spectra of a given cabbage leaf, resulting in 48 and 54 replicates per treatment in 2009 and 2011, respectively. The following "traditional" spectral variables were computed from the smoothed and averaged spectra: 1) Brightness, which constitutes an estimate of the area under the spectral curve or 
total light reflected by the leaves, was calculated as the average reflectance $\left(R_{\text {av }}\right)$, between 270 and $650 \mathrm{~nm} .2$ ) Purity of reflectance (Chroma) was calculated as the difference between maximum and minimum reflectance divided by average reflectance $\left[\left(\mathbf{R}_{\max }-\mathbf{R}_{\min }\right) /\right.$ $R_{a v}$. 3) The relative amount of $U V$ reflectance or $U V$ chroma was calculated as reflectance in the UV range $(270-400 \mathrm{~nm})$ divided by total reflectance $\left[\left(\mathrm{R}_{270}\right.\right.$ $\left.400 / R_{270-650}\right) \times 100$ ] and expressed as a percentage. 4) Hue $\left(\lambda_{\max }\right)$ was determined by the wavelength location of maximum reflectance.

In addition, we calculated three additional spectral variables of brightness based on known properties of thrips spectral sensitivity in F. occidentalis and $C$. phaseoli (Matteson et al. 1992, Mazza et al. 2010). Although the range of visual sensitivity and the photopigments that T. tabaci possess remain unknown, we hypothesized that T. tabaci has three potential photoreceptor systems with different (but partly overlapping) ranges of sensitivity. We use the term photoreceptor system to describe 1) traditional photoreceptor cells that undergo chemical changes in response to different light wavelengths and 2) traditional photoreceptor cells coupled with fluorescence in the eye and/or internal filters that block longer UV wavelengths (Mazza et al. 2010). The average reflectance (brightness) was computed from the recorded reflectance spectra of cabbage leaves in the range of sensitivity of all three theoretical photoreceptor systems of T. tabaci. Note that this type of analysis is not modeling sensitivity based on photopigment data (such as in Stoddard and Prum 2008), rather we are simply dividing up the spectrum to reflect where potential peaks of photosensitivity may be for T. tabaci. Accordingly, the average reflectance was computed in the range of sensitivity of the (5) first, 275-375 nm $\left(\mathrm{R}_{\mathrm{av1}}\right)$, (6) second, 275-400 $\mathrm{nm}\left(\mathrm{R}_{\mathrm{av} 2}\right)$, and (7) third, $400-650 \mathrm{~nm}\left(\mathrm{R}_{\mathrm{av} 3}\right)$ theoretical photoreceptor systems of T. tabaci. No blue receptor was hypothesized for $T$. tabaci, as was done in a previous study (Diaz-Montano et al. 2012), because its existence was not supported by the available electrophysiological data from $F$. occidentalis (Matteson et al. 1992). All reflectance spectrometry variables were computed for head leaves (i.e., Head_ $R_{\text {av }}$ ) and old leaves (i.e., Old_ $R_{a v}$ ), as well as their contrast $\left(\right.$ Contr_ $\left.R_{a v}\right)$ : computed value of the head leaf divided by that of the old leaf of the same cabbage plant.

Statistical Analysis. The generalized estimating equations method was used for modeling the effects of variety and kaolin clay treatment on all measured variables with plot (2009) and plot and time (2011) as covariate. For proportional abundance and actual counts of T. tabaci adults (both years), cabbage head weight at early head formation (both years), damage ratings (only in 2009), and number of damaged leaves (only in 2009), we developed a Poisson regression model on the log-transformed data. For cabbage head weight at harvest (only in 2009), and all computed reflectance spectrometry variables (both years), except UV chroma, a normal regression model was used on the log-transformed data. For UV chroma (both years), a normal regression model was used on the original data. Data are presented by estimated means and $95 \%$ Wald confidence limits. For separating estimated means of variables, Bonferroni test was performed both within a treatment between varieties and within a variety between treatments. Spearman's rank correlation test was performed between the estimated means of variables.

\section{Results}

Early Head Formation. In 2009, there was a significant effect of variety $\left(\chi^{2}=26.04 ; \mathrm{df}=5 ; P<0.001\right)$ and kaolin clay treatment $\left(\chi^{2}=16.91\right.$; df $=1 ; P<$ 0.001 ) on actual counts of $T$. tabaci adults, but proportional abundance was only dependent on variety $\left(\chi^{2}=30.15 ; \mathrm{df}=5 ; P<0.001\right)$ and not on treatment $\left(\chi^{2}=0.34 ; \mathrm{df}=1 ; P>0.557\right)$. The interaction between variety and treatment was very close to significant on actual counts of $T$. tabaci adults $\left(\chi^{2}=10.51 ; \mathrm{df}=5 ; P>\right.$ 0.062 ) and actually significant on proportional abundance $\left(\chi^{2}=11.97 ; \mathrm{df}=5 ; P<0.035\right)$. There was no plot effect on either actual counts $\left(\chi^{2}=1.22\right.$; $\mathrm{df}=2$; $P>0.543)$ or proportional abundance $\left(\chi^{2}=0.004\right.$; $\mathrm{df}=2 ; P>0.998)$ of thrips adults. Susceptible cabbage varieties had significantly higher proportion of thrips adults than resistant ones in both treatments (Table 1). Kaolin clay treatment increased the proportional abundance only on the resistant variety Balashi $(P<$ 0.022). An almost identical order of susceptibility was established by the actual count of thrips adults (Table 1). However, the kaolin clay treatment increased the abundance of $T$. tabaci adults on all varieties but Bloktor. There were mainly first- and second-stage larvae and a few prepupae found with adults on head-forming cabbage leaves. Mean cabbage head weight did vary between varieties but it was statistically identical between treatments (Table 1 ).

In 2011, there was a significant effect of variety on actual counts of thrips adults $\left(\chi^{2}=21.75\right.$; $\mathrm{df}=5 ; P<$ $0.001)$ and proportional abundance $\left(\chi^{2}=26.47\right.$; $\mathrm{df}=$ $5 ; P<0.001)$. Neither thrips abundance $\left(\chi^{2}=0.013\right.$; df $=1 ; P>0.911)$ nor proportional abundance $\left(\chi^{2}=\right.$ $0.94 ; \mathrm{df}=1 ; P>0.333)$ depended on kaolin clay treatment. The interaction between variety and treatment was significant on actual counts of $T$. tabaci adults $\left(\chi^{2}=11.43\right.$;f $\left.=5 ; P>0.043\right)$ and very close to significant on proportional abundance $\left(\chi^{2}=10.97\right.$; $\mathrm{df}=5 ; P<0.052)$. There was no plot effect on either actual counts $\left(\chi^{2}=2.28\right.$; df $\left.=2 ; P>0.685\right)$ or proportional abundance $\left(\chi^{2}=1.14 ; \mathrm{df}=2 ; P>0.888\right)$ of thrips adults this year either. However, actual counts of thrips adults varied significantly based on time of sampling $\left(\chi^{2}=14.78\right.$; $\left.\mathrm{df}=5 ; P<0.011\right)$ but proportional abundance did not $\left(\chi^{2}=0.093\right.$; $\mathrm{df}=5 ; P>$ $0.999)$. Susceptible cabbage varieties had again a significantly higher proportion of thrips adults than resistant ones in both treatments (Table 2). These marked differences were reflected by the actual count of thrips adults as well (Table 2). There were mainly first- and second-stage larvae and a few prepupae and pupae found with adults on head-forming cabbage 
Table 1. Proportional abundance and actual count of Thrips tabaci adults, and cabbage head weight measured at early head formation in 2009

\begin{tabular}{|c|c|c|c|c|c|c|c|c|c|c|}
\hline \multirow{3}{*}{$\operatorname{Tr}^{a}$} & \multirow{3}{*}{ Variety } & \multicolumn{3}{|c|}{ Proportional abundance } & \multicolumn{3}{|c|}{ Thrips adults } & \multicolumn{3}{|c|}{ Head weight } \\
\hline & & \multirow{2}{*}{ Mean (\%) } & \multicolumn{2}{|c|}{ Wald CL ${ }^{b}$} & \multirow{2}{*}{ Mean } & \multicolumn{2}{|c|}{ Wald CL ${ }^{b}$} & \multirow{2}{*}{ Mean (g) } & \multicolumn{2}{|c|}{ Wald CL ${ }^{b}$} \\
\hline & & & Lower & Upper & & Lower & Upper & & Lower & Upper \\
\hline $\mathrm{C}$ & Balashi & $6.2 \mathrm{a}^{*}$ & 4.1 & 8.2 & $0.5 \mathrm{a}^{*}$ & 0.3 & 0.8 & $51.6 \mathrm{~b}$ & 36.9 & 72.2 \\
\hline $\mathrm{C}$ & Bloktor & $10.9 \mathrm{ab}$ & 6.1 & 15.7 & $0.8 \mathrm{ab}$ & 0.5 & 1.3 & $24.2 \mathrm{a}$ & 19.6 & 29.9 \\
\hline $\mathrm{C}$ & Green Gem & $33.2 \mathrm{c}$ & 25.9 & 40.4 & $3.0 c^{*}$ & 2.3 & 4.0 & $58.3 \mathrm{~b}$ & 45.5 & 74.7 \\
\hline $\mathrm{C}$ & Hurricane & $22.9 \mathrm{c}$ & 21.8 & 24.0 & $1.7 \mathrm{bc}^{*}$ & 1.5 & 2.0 & $42.7 \mathrm{~b}$ & 36.1 & 50.6 \\
\hline $\mathrm{C}$ & Quisor & $20.4 \mathrm{bc}$ & 16.8 & 24.1 & $1.5 \mathrm{~b} *$ & 1.2 & 1.7 & $26.5 \mathrm{a}$ & 22.6 & 31.0 \\
\hline $\mathrm{C}$ & Riana & $06.4 \mathrm{a}$ & 4.8 & 7.9 & $0.5 \mathrm{a}^{*}$ & 0.3 & 0.8 & $64.3 \mathrm{ab}$ & 36.8 & 112.2 \\
\hline $\mathrm{K}$ & Balashi & $11.4 \mathrm{~b}$ & 9.4 & 13.5 & $2.2 \mathrm{~b}$ & 1.8 & 2.6 & $59.5 \mathrm{~cd}$ & 42.9 & 82.3 \\
\hline $\mathrm{K}$ & Bloktor & $05.9 \mathrm{a}$ & 4.6 & 7.3 & $1.1 \mathrm{a}$ & 0.9 & 1.3 & $23.4 \mathrm{a}$ & 20.1 & 27.1 \\
\hline $\mathrm{K}$ & Green Gem & $31.1 \mathrm{c}$ & 23.6 & 38.7 & $6.2 \mathrm{e}$ & 4.7 & 8.3 & $75.5 \mathrm{~d}$ & 50.1 & 114.0 \\
\hline $\mathrm{K}$ & Hurricane & $18.9 \mathrm{c}$ & 16.5 & 21.3 & $3.6 \mathrm{~cd}$ & 3.2 & 3.9 & $34.4 \mathrm{bc}$ & 31.2 & 38.0 \\
\hline $\mathrm{K}$ & Quisor & $22.8 \mathrm{c}$ & 18.6 & 27.0 & $4.2 \mathrm{de}$ & 3.6 & 5.0 & $28.4 \mathrm{ab}$ & 21.5 & 37.5 \\
\hline $\mathrm{K}$ & Riana & $10.0 \mathrm{ab}$ & 7.6 & 12.4 & $1.9 \mathrm{abc}$ & 1.3 & 2.7 & 43.1bcd & 36.3 & 51.2 \\
\hline
\end{tabular}

Within a treatment, estimated means followed by different letters are significantly different $(P<0.05$; Bonferroni test $)$.

Within a variety, an asterisk indicates significant differences between treatments $(P<0.05$; Bonferroni test $)$

${ }^{a} \mathrm{Tr}$, treatment; $\mathrm{C}$, untreated control; $\mathrm{K}$, treated with kaolin clay.

${ }^{b}$ Wald CL: $95 \%$ Wald CLs of the estimated mean.

leaves. Mean cabbage head weight did vary between varieties again and it was statistically identical between treatments, with the only exception of the variety Green Gem $(P<0.001)$ (Table 2$)$.

Harvest Maturity. There was a significant effect of variety $\left(\chi^{2}=22.66 ; \mathrm{df}=5 ; P<0.001\right)$ and kaolin clay treatment $\left(\chi^{2}=7.29\right.$; $\left.\mathrm{df}=1 ; P<0.007\right)$ on damage ratings. Similarly, the number of damaged head-forming leaves was dependent on both variety $\left(\chi^{2}=28.56\right.$; $\mathrm{df}=5 ; P<0.001)$ and treatment $\left(\chi^{2}=11.18 ; \mathrm{df}=1\right.$; $P<0.001)$. The interaction between variety and treatment was close to significant both on damage $\left(\chi^{2}=\right.$ $7.92 ; \mathrm{df}=5 ; P>0.160)$ and number of damaged leaves $\left(\chi^{2}=9.40 ; \mathrm{df}=5 ; P<0.094\right)$. There was no plot effect on either damage ratings $\left(\chi^{2}=2.57 ; \mathrm{df}=2 ; P>0.277\right)$ or number of damaged head-forming leaves $\left(\chi^{2}=1.27\right.$; $\mathrm{df}=2 ; P>0.531)$. Susceptible cabbage varieties had significantly higher damage ratings than resistant ones in both treatments (Table 3). Kaolin clay treatment increased the damage ratings on Balashi $(P<0.001)$, Green Gem $(P<0.029)$, and Hurricane $(P<0.001)$. The number of damaged leaves was even more distinctly different between susceptible and resistant cabbage varieties (Table 3). More head-forming leaves were damaged by thrips on kaolin clay-treated Balashi $(P<0.001)$, Green Gem $(P<0.001)$, and Riana $(P<0.037)$ than on untreated plants. Mean cabbage head weight did vary between varieties but it was identical between treatments, with the only exception of Balashi $(P<0.001)$ (Table 3$)$. The correlation between actual count of thrips adults at early head formation and damage ratings, as well as number of damaged leaves at harvest maturity, was significant (Table 4). An even stronger correlation was found between proportional abundance at early head formation and damage ratings as well as number of damaged leaves at harvest maturity.

Table 2. Proportional abundance and actual count of Thrips tabaci adults, and cabbage head weight measured at early head formation in 2011 (combined for all sampling events)

\begin{tabular}{|c|c|c|c|c|c|c|c|c|c|c|}
\hline \multirow{3}{*}{$\operatorname{Tr}^{a}$} & \multirow{3}{*}{ Variety } & \multicolumn{3}{|c|}{ Proportional abundance } & \multicolumn{3}{|c|}{ Thrips adults } & \multicolumn{3}{|c|}{ Head weight } \\
\hline & & \multirow{2}{*}{ Mean (\%) } & \multicolumn{2}{|c|}{ Wald CL $^{b}$} & \multirow{2}{*}{ Mean } & \multicolumn{2}{|c|}{ Wald CL $^{b}$} & \multirow{2}{*}{ Mean $(g)$} & \multicolumn{2}{|c|}{ Wald CL $^{b}$} \\
\hline & & & Lower & Upper & & Lower & Upper & & Lower & Upper \\
\hline $\mathrm{C}$ & Balashi & $6.0 \mathrm{a}$ & 5.2 & 6.8 & $1.4 \mathrm{a}$ & 1.2 & 1.6 & $36.6 \mathrm{~b}$ & 31.0 & 43.1 \\
\hline $\mathrm{C}$ & Bloktor & $12.8 \mathrm{~b}$ & 10.8 & 14.8 & $3.3 \mathrm{~b}$ & 2.9 & 3.9 & $19.3 \mathrm{a}$ & 16.7 & 22.3 \\
\hline $\mathrm{C}$ & Green Gem & $25.5 \mathrm{~d}$ & 22.9 & 28.1 & $5.4 \mathrm{c}$ & 4.9 & 6.0 & $61.3 c^{*}$ & 58.8 & 64.0 \\
\hline $\mathrm{C}$ & Hurricane & $31.6 \mathrm{~d}$ & 29.0 & 34.1 & $7.5 \mathrm{~d}$ & 7.0 & 8.1 & $21.4 \mathrm{a}$ & 20.6 & 22.1 \\
\hline $\mathrm{C}$ & Quisor & $18.2 \mathrm{c}$ & 16.7 & 19.8 & $4.2 \mathrm{~b}$ & 3.8 & 4.7 & $26.4 \mathrm{ab}$ & 22.9 & 30.5 \\
\hline $\mathrm{C}$ & Riana & $5.3 \mathrm{a}$ & 4.3 & 6.2 & $1.3 \mathrm{a}$ & 1.0 & 1.7 & $34.9 \mathrm{~b}$ & 32.3 & 37.6 \\
\hline $\mathrm{K}$ & Balashi & $7.1 \mathrm{a}$ & 5.9 & 8.4 & $1.5 \mathrm{a}$ & 1.3 & 1.8 & $40.0 \mathrm{c}$ & 38.2 & 42.0 \\
\hline $\mathrm{K}$ & Bloktor & $11.5 \mathrm{ab}$ & 8.5 & 14.4 & $2.7 \mathrm{~b}$ & 2.1 & 3.5 & $20.2 \mathrm{a}$ & 17.9 & 22.8 \\
\hline $\mathrm{K}$ & Green Gem & $29.5 \mathrm{c}$ & 25.9 & 33.1 & $6.9 \mathrm{c}$ & 6.2 & 7.7 & $74.7 \mathrm{~d}$ & 70.8 & 78.8 \\
\hline K & Hurricane & $29.4 \mathrm{c}$ & 26.7 & 32.2 & $6.8 \mathrm{c}$ & 6.0 & 7.7 & $22.9 \mathrm{a}$ & 22.0 & 23.8 \\
\hline K & Quisor & $14.3 \mathrm{~b}$ & 12.1 & 16.6 & $3.3 \mathrm{~b}$ & 2.8 & 3.8 & $30.9 \mathrm{~b}$ & 29.6 & 32.3 \\
\hline K & Riana & $7.6 \mathrm{a}$ & 6.8 & 8.5 & $1.7 \mathrm{a}$ & 1.4 & 1.9 & $40.1 \mathrm{c}$ & 38.9 & 41.4 \\
\hline
\end{tabular}

Within a treatment, estimated means followed by different letters are significantly different $(P<0.05$; Bonferroni test $)$.

Within a variety, an asterisk indicates significant differences between treatments $(P<0.05$; Bonferroni test $)$.

${ }^{a}$ Tr: treatment, C: untreated control, K: treated with kaolin clay.

${ }^{b}$ Wald CL: $95 \%$ Wald confidence limits of the estimated mean. 
Table 3. Damage ratings, number of damaged leaves, and cabbage head weight measured at harvest maturity in 2009

\begin{tabular}{|c|c|c|c|c|c|c|c|c|c|c|}
\hline \multirow{3}{*}{$\operatorname{Tr}^{a}$} & \multirow{3}{*}{ Variety } & \multicolumn{3}{|c|}{ Damage ratings } & \multicolumn{3}{|c|}{ Damaged leaves } & \multicolumn{3}{|c|}{ Head weight } \\
\hline & & \multirow{2}{*}{ Mean } & \multicolumn{2}{|c|}{ Wald $\mathrm{CL}^{b}$} & \multirow{2}{*}{ Mean } & \multicolumn{2}{|c|}{ Wald CL ${ }^{b}$} & \multirow{2}{*}{ Mean (g) } & \multicolumn{2}{|c|}{ Wald CL ${ }^{b}$} \\
\hline & & & Lower & Upper & & Lower & Upper & & Lower & Upper \\
\hline $\mathrm{C}$ & Balashi & $0.2 \mathrm{a}^{*}$ & 0.19 & 0.25 & $1.5 \mathrm{a}^{*}$ & 1.3 & 1.6 & $1,989 \mathrm{~d}^{*}$ & 1,923 & 2,057 \\
\hline $\mathrm{C}$ & Bloktor & $0.4 \mathrm{ab}$ & 0.28 & 0.62 & $3.5 \mathrm{~b}$ & 2.8 & 4.5 & $1,038 \mathrm{a}$ & 921 & 1,171 \\
\hline $\mathrm{C}$ & Green Gem & $3.1 c^{*}$ & 2.91 & 3.23 & $10.8 \mathrm{~d}^{*}$ & 10.5 & 11.2 & $1,917 \mathrm{~cd}$ & 1,760 & 2,088 \\
\hline $\mathrm{C}$ & Hurricane & $3.1 c^{*}$ & 2.86 & 3.28 & $14.0 \mathrm{e}$ & 13.2 & 15.0 & $1,525 \mathrm{~b}$ & 1,427 & 1,631 \\
\hline $\mathrm{C}$ & Quisor & $0.8 b$ & 0.65 & 1.08 & $6.2 \mathrm{c}$ & 5.4 & 7.2 & $1,357 \mathrm{abc}$ & 1,069 & 1,723 \\
\hline $\mathrm{C}$ & Riana & $0.3 \mathrm{a}$ & 0.19 & 0.40 & $1.7 \mathrm{a}^{*}$ & 1.4 & 1.9 & $2,424 \mathrm{e}$ & 2,365 & 2,486 \\
\hline K & Balashi & $0.3 \mathrm{a}$ & 0.30 & 0.41 & $2.0 \mathrm{a}$ & 1.9 & 2.1 & $2,413 \mathrm{~d}$ & 2,318 & 2,513 \\
\hline $\mathrm{K}$ & Bloktor & $0.3 \mathrm{a}$ & 0.32 & 0.34 & $3.3 \mathrm{~b}$ & 3.1 & 3.4 & $992 \mathrm{a}$ & 908 & 1,083 \\
\hline K & Green Gem & $3.6 \mathrm{c}$ & 3.42 & 3.79 & $13.2 \mathrm{~d}$ & 12.3 & 14.2 & $2,093 \mathrm{~cd}$ & 1,899 & 2,306 \\
\hline K & Hurricane & $4.0 \mathrm{c}$ & 3.82 & 4.24 & $15.1 \mathrm{~d}$ & 14.2 & 16.0 & $1,378 \mathrm{~b}$ & 1,199 & 1,583 \\
\hline $\mathrm{K}$ & Quisor & $0.9 \mathrm{~b}$ & 0.80 & 1.07 & $6.9 \mathrm{c}$ & 6.4 & 7.4 & $1,710 \mathrm{bc}$ & 1,498 & 1,952 \\
\hline K & Riana & $0.4 \mathrm{a}$ & 0.33 & 0.40 & $2.1 \mathrm{a}$ & 2.1 & 2.1 & $2,324 \mathrm{~cd}$ & 1,964 & 2,751 \\
\hline
\end{tabular}

Within a treatment, estimated means followed by different letters are significantly different $(P<0.05$; Bonferroni test $)$.

Within a variety, an asterisk indicates significant differences between treatments $(P<0.05$; Bonferroni test $)$.

${ }^{a} \mathrm{Tr}$, treatment; $\mathrm{C}$, untreated control; $\mathrm{K}$, treated with kaolin clay.

${ }^{b}$ Wald CL: $95 \%$ Wald CLs of the estimated mean.

Reflectance Spectrophotometry. In 2009, there was a significant effect of variety $(P<0.05)$ on all computed reflectance variables but Head $R_{\text {av }}\left(\chi^{2}=8.08\right.$; $\mathrm{df}=5 ; P=0.152)$ and Head_ $\mathrm{R}_{\text {av3 }}\left(\chi^{\overline{2}}=7.63 ; \mathrm{df}=5\right.$; $P=0.178)$. Kaolin clay treatment increased the spectral values for all varieties (all $P$ values $<0.05$ ) and there was no plot effect (all $P$ values $>0.05$ ). In 2011, the effect of variety and treatment on all computed reflectance variables was significant (all $P$ values $<0.05$ ) in our models. There was no plot effect (all $P$ values $>0.05$ ) but all computed reflectance variables seemed to vary based on the time of sampling (all $P$ values $<0.05$ ). There was a high degree of consistency in the values of all computed variables between the 2 yr. An example for this is presented for brightness of old leaves in Table 5. The mean brightness of old leaves of any variety was greater in 2011 than in 2009, and it was always greater on kaolin clay-treated than on untreated plants. Rather than presenting the estimated means for the other 20 variables of reflectance, the result of the performed Spearman's correlation test between antixenosis and all reflectance variables is presented in Table 6 (2009) and Table 7 (2011). In 2009 , there was no significant correlation between proportional abundance of thrips adults and any of the 21 variables. However, the correlation between the actual count of thrips adults and eight variables was significant (Table 6). The four that yielded the highest correlation coefficients of the eight were the four

Table 4. Correlation between antixenosis and overall resistance of cabbage to Thrips tabaci adults

\begin{tabular}{|c|c|c|c|c|c|c|}
\hline \multirow{3}{*}{$\begin{array}{l}\text { Measure of } \\
\text { antixenosis }\end{array}$} & \multicolumn{6}{|c|}{ Measure of overall resistance } \\
\hline & \multicolumn{3}{|c|}{ Damage ratings } & \multicolumn{3}{|c|}{ Damaged leaves } \\
\hline & $\rho^{a}$ & $\mathrm{df}^{b}$ & $P^{c}$ & $\rho^{a}$ & $\mathrm{df}^{b}$ & $P^{c}$ \\
\hline Thrips adults & 0.774 & 10 & 0.003 & 0.683 & 10 & 0.014 \\
\hline Proportional abundance & 0.832 & 10 & 0.001 & 0.769 & 10 & 0.003 \\
\hline
\end{tabular}

${ }^{a}$ Spearman's correlation coefficient (rho).

${ }^{b}$ Degrees of freedom $(n-2)$.

${ }^{c}$ Significance. brightness variables of old leaves $\left(R_{\mathrm{av}}, \mathrm{R}_{\mathrm{av1}}, \mathrm{R}_{\mathrm{av} 2}\right.$, and $R_{\text {av3 }}$ ), with each value showing a positive correlation. On the contrary, there was no significant correlation between either actual count or proportional abundance of thrips adults and any of the 21 reflectance variables in 2011 (Table 7).

\section{Discussion}

Despite differences in environmental conditions between New York and the location of a previous study in Hungary (Fail et al. 2008), the established order of the cabbage varieties, based on the degree of thrips damage, was identical at both locations. The damage ratings in this study were either equal or somewhat smaller but this could be the result of a lower thrips pressure in New York in 2009. Nonetheless, the result of damage assessment confirmed the level of overall resistance to T. tabaci in the six white cabbage varieties. Taking into account the number of thrips-damaged head-forming leaves, the difference in overall thrips resistance between the varieties becomes even more distinct.

It is well-known that thrips can live and reproduce on cabbage frame leaves and cause silvering damage. However, such damage is inconsequential compared with damage to the marketable part of cabbage, that is, the head. The overall thrips resistance of a cabbage line or variety is measured by the extent of thrips damage on head-forming leaves only. In the first part of head formation, thrips could potentially move in and out of the loose head without any difficulty, but after a certain point in the development of the cabbage head, such movement becomes restricted, even for these small insects. During thrips damage assessment, we often encountered leaf surfaces of various sizes where thrips density and damage were extremely high and sharply delineated by a discrete line, despite being surrounded by undamaged surface. These areas were bordered by veins of adjacent leaves that were pressed against each other tightly creating a small isolated 
Table 5. Brightness of old leaves of cabbage plants $\left(R_{\text {av }}\right)$ in 2009 and 2011 (combined for all sampling events in 2011 )

\begin{tabular}{|c|c|c|c|c|c|c|c|}
\hline \multirow{3}{*}{$\operatorname{Tr}^{a}$} & \multirow{3}{*}{ Variety } & \multicolumn{3}{|c|}{$2009 \mathrm{R}_{\mathrm{av}}$} & \multicolumn{3}{|c|}{$2011 \mathrm{R}_{\mathrm{av}}$} \\
\hline & & \multirow{2}{*}{ Mean } & \multicolumn{2}{|c|}{ Wald CL ${ }^{b}$} & \multirow{2}{*}{ Mean } & \multicolumn{2}{|c|}{ Wald CL ${ }^{b}$} \\
\hline & & & Lower & Upper & & Lower & Upper \\
\hline $\mathrm{C}$ & Balashi & $15.8 b^{*}$ & 15.3 & 16.3 & $20.6 a^{*}$ & 19.5 & 21.8 \\
\hline $\mathrm{C}$ & Bloktor & $19.1 c^{*}$ & 18.6 & 19.7 & $25.6 b^{*}$ & 24.8 & 26.5 \\
\hline $\mathrm{C}$ & Green Gem & $18.2 \mathrm{bcd}^{*}$ & 16.8 & 19.8 & $26.3 b^{*}$ & 25.6 & 26.9 \\
\hline $\mathrm{C}$ & Hurricane & $19.5 \mathrm{~cd}^{*}$ & 18.2 & 21.0 & $26.5 \mathrm{~b} *$ & 26.0 & 27.0 \\
\hline $\mathrm{C}$ & Quisor & $20.6 \mathrm{~d} *$ & 20.5 & 20.8 & $31.1 c^{*}$ & 30.7 & 31.6 \\
\hline $\mathrm{C}$ & Riana & $14.2 \mathrm{a}^{*}$ & 14.0 & 14.5 & $20.5 a^{*}$ & 20.1 & 21.0 \\
\hline K & Balashi & $22.7 \mathrm{a}$ & 21.2 & 24.4 & $41.2 \mathrm{ab}$ & 40.4 & 42.0 \\
\hline K & Bloktor & $27.4 \mathrm{~b}$ & 26.5 & 28.4 & $43.8 \mathrm{c}$ & 42.5 & 45.2 \\
\hline $\mathrm{K}$ & Green Gem & $31.6 \mathrm{~cd}$ & 30.5 & 32.6 & $41.1 \mathrm{bc}$ & 40.5 & 41.7 \\
\hline $\mathrm{K}$ & Hurricane & $27.8 \mathrm{~b}$ & 26.9 & 28.7 & $40.6 \mathrm{ab}$ & 39.8 & 41.3 \\
\hline $\mathrm{K}$ & Quisor & $33.0 \mathrm{~d}$ & 31.3 & 34.7 & $39.5 \mathrm{a}$ & 38.8 & 40.2 \\
\hline K & Riana & $29.8 \mathrm{c}$ & 29.1 & 30.5 & $40.3 \mathrm{ab}$ & 38.7 & 41.9 \\
\hline
\end{tabular}

Within a treatment, estimated means followed by different letters are significantly different $(P<0.05$; Bonferroni test $)$.

Within a variety, an asterisk indicates significant differences between treatments $(P<0.05$; Bonferroni test $)$.

${ }^{a} \mathrm{Tr}$, treatment; $\mathrm{C}$, untreated control; $\mathrm{K}$, treated with kaolin clay.

${ }^{b}$ Wald CL: $95 \%$ Wald CLs of the estimated mean.

pocket inside the cabbage head from which even the small immature stages of $T$. tabaci could not escape. It appears that thrips find more favorable environmental conditions inside the cabbage head than on frame leaves, but they also become trapped inside the head and their movement is greatly restricted. Once the movement of thrips in and out of the cabbage head becomes greatly restricted, only those thrips inside the head could contribute to head damage. We consider the preference of thrips toward head-forming or frame leaves in this unrestricted movement phase, even if it

Table 6. Correlation between antixenosis and computed light reflectance variables of cabbage leaves in 2009

\begin{tabular}{|c|c|c|c|c|c|c|}
\hline \multirow{3}{*}{$\begin{array}{c}\text { Reflectance } \\
\text { variables }^{a}\end{array}$} & \multicolumn{6}{|c|}{ Measure of antixenosis } \\
\hline & \multicolumn{3}{|c|}{ Thrips adults } & \multicolumn{3}{|c|}{$\begin{array}{l}\text { Proportional } \\
\text { abundance }\end{array}$} \\
\hline & $\rho^{b}$ & $\mathrm{df}^{c}$ & $P^{d}$ & $\rho^{b}$ & $\mathrm{df}^{c}$ & $P^{d}$ \\
\hline Head_R $\mathrm{R}_{\mathrm{av}}$ & 0.641 & 10 & 0.025 & 0.077 & 10 & 0.812 \\
\hline Head_R & 0.529 & 10 & 0.077 & 0.119 & 10 & 0.713 \\
\hline Head_R $\mathrm{R}_{\mathrm{av} 2}$ & 0.529 & 10 & 0.077 & 0.119 & 10 & 0.713 \\
\hline Head_- $R_{a v 3}$ & 0.585 & 10 & 0.046 & -0.007 & 10 & 0.983 \\
\hline Head_Chroma & -0.396 & 10 & 0.203 & -0.105 & 10 & 0.746 \\
\hline Head_UVChroma & 0.098 & 10 & 0.762 & 0.105 & 10 & 0.746 \\
\hline Head ${ }_{-}^{-} \lambda_{\max }$ & -0.368 & 10 & 0.239 & -0.221 & 10 & 0.491 \\
\hline Old_ $\overline{\mathrm{R}}_{\mathrm{av}}$ & 0.760 & 10 & 0.004 & 0.252 & 10 & 0.430 \\
\hline Old_- $\mathrm{R}_{\mathrm{av} 1}$ & 0.683 & 10 & 0.014 & 0.252 & 10 & 0.430 \\
\hline Old_- $\mathrm{R}_{\mathrm{av} 2}$ & 0.739 & 10 & 0.006 & 0.266 & 10 & 0.404 \\
\hline Old_- $R_{\text {av3 }}$ & 0.760 & 10 & 0.004 & 0.252 & 10 & 0.430 \\
\hline Old_Chroma & -0.564 & 10 & 0.056 & -0.196 & 10 & 0.542 \\
\hline Old_UVChroma & 0.179 & 10 & 0.579 & 0.566 & 10 & 0.055 \\
\hline $\operatorname{Old}^{-} \lambda_{\max }$ & 0.242 & 10 & 0.449 & -0.392 & 10 & 0.208 \\
\hline Contr_ $\mathrm{R}_{\mathrm{av}}$ & -0.529 & 10 & 0.077 & -0.238 & 10 & 0.457 \\
\hline Contr_R $\mathrm{R}_{\text {av1 }}$ & -0.536 & 10 & 0.073 & -0.357 & 10 & 0.255 \\
\hline Contr_R $\mathrm{R}_{\text {av2 }}$ & -0.508 & 10 & 0.092 & -0.245 & 10 & 0.443 \\
\hline Contr_ $\mathbf{R}_{\text {av3 }}$ & -0.578 & 10 & 0.049 & -0.168 & 10 & 0.602 \\
\hline Contr_Chroma & 0.620 & 10 & 0.032 & 0.350 & 10 & 0.265 \\
\hline Contr UVChroma & -0.226 & 10 & 0.479 & -0.480 & 10 & 0.114 \\
\hline $\operatorname{Contr}_{-}^{-} \lambda_{\max }$ & -0.431 & 10 & 0.162 & 0.231 & 10 & 0.471 \\
\hline
\end{tabular}

${ }^{a}$ See text for explanation of abbreviations of computed reflectance variables.

${ }^{b}$ Spearman's correlation coefficient (rho).

${ }^{c}$ Degrees of freedom $(n-2)$.

${ }^{d}$ Significance. only results in a within-plant distributional difference between susceptible and resistant varieties and in no difference in thrips abundance on the whole plant basis, as the result of their "choice." Because of these considerations, we believe that the number of thrips adults in the head at an early stage of head formation, before the emergence of the first adults that developed on the plant and could be affected by antibiosis, indicates solely antixenotic resistance of the variety. Because there was not a single newly emerged $T$.

Table 7. Correlation between antixenosis and computed light reflectance variables of cabbage leaves in 2011 (combined for all sampling events)

\begin{tabular}{|c|c|c|c|c|c|c|}
\hline \multirow{3}{*}{$\begin{array}{c}\text { Reflectance } \\
\text { variables }^{a}\end{array}$} & \multicolumn{6}{|c|}{ Measure of antixenosis } \\
\hline & \multicolumn{3}{|c|}{ Thrips adults } & \multicolumn{3}{|c|}{$\begin{array}{l}\text { Proportional } \\
\text { abundance }\end{array}$} \\
\hline & $\rho^{b}$ & $\mathrm{df}^{c}$ & $P^{d}$ & $\rho^{b}$ & $\mathrm{df}^{c}$ & $P^{d}$ \\
\hline Head_R $\mathrm{av}$ & -0.280 & 10 & 0.379 & -0.252 & 10 & 0.430 \\
\hline Head_- $\mathrm{R}_{\mathrm{av} 1}$ & -0.336 & 10 & 0.286 & -0.308 & 10 & 0.331 \\
\hline Head_R $\mathrm{R}_{\mathrm{av} 2}$ & -0.336 & 10 & 0.286 & -0.308 & 10 & 0.331 \\
\hline Head_R $\mathrm{R}_{\mathrm{av} 3}$ & -0.280 & 10 & 0.379 & -0.252 & 10 & 0.430 \\
\hline Head Chroma & 0.133 & 10 & 0.681 & 0.084 & 10 & 0.795 \\
\hline Head_UVChroma & -0.014 & 10 & 0.966 & 0.014 & 10 & 0.966 \\
\hline Head ${ }^{-} \lambda_{\max }$ & 0.018 & 10 & 0.957 & 0.039 & 10 & 0.905 \\
\hline Old_ $\overline{\mathrm{R}}_{\mathrm{av}}$ & 0.266 & 10 & 0.404 & 0.294 & 10 & 0.354 \\
\hline Old_- $\mathrm{R}_{\mathrm{av} 1}$ & 0.308 & 10 & 0.331 & 0.343 & 10 & 0.276 \\
\hline Old_- $\mathrm{R}_{\mathrm{av} 2}$ & 0.308 & 10 & 0.331 & 0.343 & 10 & 0.276 \\
\hline Old_- R & 0.252 & 10 & 0.430 & 0.273 & 10 & 0.391 \\
\hline Old_Chroma & -0.378 & 10 & 0.226 & -0.371 & 10 & 0.236 \\
\hline Old_UVChroma & 0.259 & 10 & 0.417 & 0.252 & 10 & 0.430 \\
\hline Old $-\lambda_{\max }$ & -0.203 & 10 & 0.527 & -0.189 & 10 & 0.557 \\
\hline Contr_ $\mathrm{R}_{\mathrm{av}}$ & -0.217 & 10 & 0.499 & -0.266 & 10 & 0.404 \\
\hline Contr_ $\mathrm{R}_{\mathrm{av} 1}$ & -0.503 & 10 & 0.095 & -0.545 & 10 & 0.067 \\
\hline Contr_ $\mathrm{R}_{\mathrm{av} 2}$ & -0.287 & 10 & 0.366 & -0.329 & 10 & 0.297 \\
\hline Contr_R $R_{\text {av3 }}$ & -0.235 & 10 & 0.463 & -0.284 & 10 & 0.372 \\
\hline Contr_Chroma & 0.147 & 10 & 0.649 & 0.126 & 10 & 0.697 \\
\hline Contr_UVChroma & -0.126 & 10 & 0.697 & -0.084 & 10 & 0.795 \\
\hline Contr_- $\lambda_{\max }$ & 0.175 & 10 & 0.587 & 0.154 & 10 & 0.633 \\
\hline
\end{tabular}

${ }^{a}$ See text for explanation of abbreviations of computed reflectance variables.

${ }^{b}$ Spearman's correlation coefficient (rho).

${ }^{c}$ Degrees of freedom $(n-2)$.

${ }^{d}$ Significance. 
tabaci adult found on head-forming leaves of cabbage and the vast majority of immatures were still in larval stages both in 2009 and 2011, we concluded that the heat sum model predicted the development of $T$. tabaci well. Therefore, all thrips adults that we encountered during every sampling event at early head formation were considered as colonizing adults and not as progeny produced inside the cabbage head. These colonizing adults expressed a strong preference toward landing and remaining on certain cabbage varieties. The most susceptible Hurricane and Green Gem varieties were greatly preferred over the most resistant Balashi and Riana in both years. This study confirms the previous finding that Balashi and Riana have strong antixenotic resistance, whereas Bloktor and Quisor have moderate antixenotic resistance compared with Hurricane and Green Gem (Fail et al. 2008).

Host plant resistance is not an absolute measure: "The resistant variety ordinarily suffers more or less injury but always less than the susceptible ones do under the same conditions. Resistance is ordinarily measured in terms that reflect a comparison with one variety, or the average of a group, of susceptible varieties." (Painter 1951). To apply this approach in the measure of antixenotic resistance, the proportional abundance of thrips adults was computed in addition to the actual count of thrips adults in small cabbage heads. The proportional abundance is not only more in line with the concept of host plant resistance but it seems to be more stable under varying environmental conditions in this study. In 2009, the kaolin clay treatment significantly increased thrips abundance in small heads of five of the six cabbage varieties, but the proportional abundance of thrips adults barely changed: only in one case of the five. In 2011, our model predicted a significant effect of sampling time on the actual count of thrips adults, but the proportional abundance of thrips adults was not affected at all by sampling time. Based on the actual count of thrips adults in the untreated control, there was a much higher T. tabaci pressure in 2011 than in 2009, but it is not reflected by the values of proportional abundance, which were almost identical in both years.

Because the mean cabbage head weight was in the same range in 2009 and 2011 (23-76 g and 19-75 g, respectively), we concluded that cabbage plants were in the same growth stage at the time of sampling and the higher values in thrips abundance were not because of differences in plant growth but to more favorable weather conditions to T. tabaci in 2011. The proportional abundance of thrips adults was more strongly correlated to measures of overall resistance (both damage ratings and number of damaged leaves) than the actual count. Despite measuring antixenosis in a rather early phase of head formation (mean head weight at this point was $\approx 2.5 \%$, between 1.7 and $3.6 \%$, of mean head weight at harvest), variation in proportional abundance accounted for $70 \%$ of variation in damage ratings. Because of these considerations, we suggest the use of proportional abundance instead of actual insect counts as a measure of antixenotic resis- tance. It appears to be a more stable measure of antixenosis, less influenced by changes in environmental conditions that could directly affect pest pressure.

There were distinct differences in all computed light reflectance variables between the cabbage varieties in both years. As the secondary purpose of this study was to examine correlation between any light reflectance characteristic and antixenotic resistance, we presented the result of correlation tests for all of the light reflectance variables rather than their estimated means. We found the strongest correlation between actual count of thrips adults and the brightness of old cabbage leaves, but only in 2009, the year with lower T. tabaci pressure. Beside the average brightness in the entire range of our interest (between 270 and $650 \mathrm{~nm}$ ), the brightness in specific parts of this range was almost equally correlated to thrips abundance. There was no specific range of light in the proposed visual range of T. tabaci that was correlated distinctly stronger to thrips abundance than other parts of the spectrum. While none of these variables were correlated to thrips abundance in 2011, when reflectance spectra of outer head-forming leaves and old leaves of the same plant were recorded on the same day, we believe that this methodological difference between years did not affect the outcome of the reflectance measurements significantly because differences between the varieties were almost identical in both years. However, another difference between years was with regard to treatment: the kaolin clay significantly increased the brightness of leaves on all varieties in both years, but it was not correlated with higher thrips abundance in the second year of this study, only in the first year. Therefore, the observed differences in thrips abundance between the cabbage varieties may be because of differences in olfactory cues or plant traits or weather conditions (such as light intensity) that resulted in different postalighting behavior.

Because of the discrepancy in the results between years of this study, the role of visual cues for thrips must be interpreted with caution. Although it could be argued that the lack of a replicable response in 2011 is evidence that visual cues are not important (or as important as other cues) in thrips-cabbage interactions, it may be that thrips' visually based behavior is affected by other biological phenomena in this system. The overall brightness levels measured in 2011 were higher than in 2009, which might suggest a threshold effect for thrips use visual cues. Although visual systems are usually optimized for contrast detection, absolute levels of light can also influence behaviors. Finally, at least one other study has shown an effect of visual cues on thrips choice behavior; in a free-choice antixenosis experiment, T. tabaci abundance and the brightness of onion leaves were significantly correlated, especially in the UV range of light (Diaz-Montano et al. 2012). In this study, the correlations were similar to what we found in cabbage in 2009, that is, the most resistant cabbage varieties had the lowest reflectance in the UV range, whereas the most susceptible ones had the highest on their old leaves. The role of 
visual cues in the antixenotic resistance of these cabbage varieties could be confirmed by comparing trap catches of sticky boards that have light reflectance spectra exactly matching the light reflectance of these cabbage varieties.

In a laboratory study, development time and mortality rate of $T$. tabaci larvae and adults were both increased, whereas feeding damage was decreased, on kaolin-clay-treated onion leaves compared with the water-treated control. The negative effect of kaolin clay treatments on T. tabaci was confirmed in a field trial, where it decreased the abundance of thrips adults and larvae at peak population times (Larentzaki et al. 2008). However, what seemed to be a promising tool against T. tabaci in onion did not work in cabbage. Multiple spray applications of a kaolin particle-based product did not reduce the number of thrips adults inside the cabbage head in this study, which is understandable considering the shelter T. tabaci could find under the cover of outer head-forming leaves. In fact, it resulted in a two to fourfold increase in thrips abundance on five of the six cabbage varieties in 2009 . Considering that T. tabaci adults avoided feeding and oviposition on kaolin-treated onion leaves in a choice test (Larentzaki et al. 2008), it can be hypothesized that survivors of the kaolin clay treatments also avoided the old leaves of cabbage and moved into the head, resulting in the observed higher abundance on treated plants.

The current study demonstrates that antixenosis plays an important role in the overall resistance of white cabbage varieties to damage caused by T. tabaci. This study on cabbage and previous work on onions (Diaz-Montano et al. 2012) suggest that breeding for plant color, or at least light reflectance that influences T. tabaci behavior, should be an important part of an overall breeding strategy for host plant resistance to this difficult pest. However, these studies also suggest that further work is needed to link the characteristics of light reflectance in cabbage, and other crops, to the physiological perception of light in T. tabaci. At the same time, it should also be realized that antixenosis may not be the only resistance mechanism at work in T. tabaci resistance in cabbage or onion.

\section{Acknowledgments}

Bakker Brothers, Bejo Zaden B.V., Daehnfeldt A/S, and Syngenta Seeds Inc. are acknowledged for providing seeds for this study. We are grateful to Mei Cheung, Hilda Collins, Kelly R. Patel, Françoise Vermeylen, John Barnard, Géza Bujdosó, Mao Chen, John Diaz-Montano, Dan Olmstead, Kevin R. Pollard, and the crew of the Field Research Unit at the New York State Agricultural Experiment Station for helping in various aspects of this study. This research was partially funded by the New York State Cabbage Research and Development Program. The first author was supported by J. William Fulbright Fellowship, the National Development Agency (NDA), and the Hungarian Scientific Research Fund (OTKA) co-funded by EU FP7 Marie Curie Actions.

\section{References Cited}

Andaloro, J. T., K. B. Rose, A. M. Shelton, C. W. Hoy, and R. F. Becker. 1983. Cabbage growth stages. NY Food Life Sci. Bull. 101: 1-4.

Boodley, J. W., and R. Sheldrake. 1972. Cornell peat-lite mixes for commercial plant growing. Cornell Univ. Coop. Ext. Pub. Inf. Bull. 43: 1-8.

Czencz, K. 1987. The role of coloured traps in collecting thrips fauna, pp. 426-435. In J. Holman, J. Pelikan, A.F.G. Dixon, and L. Weisman (eds.), Population Structure, Genetics and Taxonomy of Aphids and Thysanoptera, p. 542. Proceedings of International Symposia, held at Smolenice, Czechoslovakia, September 9-14, 1985. SPB Academic Publishing, The Hauge, The Netherlands.

Diaz-Montano, J., J. Fail, M. Deutschlander, B. A. Nault, and A. M. Shelton. 2012. Characterization of resistance, evaluation of the attractiveness of plant odors, and effect of leaf color on different onion cultivars to onion thrips (Thysanoptera: Thripidae). J. Econ. Entomol. 105: 632641.

Edelson, J. V., and J. J. Magaro. 1988. Development of onion thrips, Thrips tabaci Lindeman, as a function of temperature. Southwest. Entomol. 13: 171-176.

Fail, J. 2006. Fejeskáposzta-fajták ellenállósága a dohánytripsszel szemben (Resistance of white cabbage varieties to onion thrips). Zöldségtermesztés 37: 21-27.

Fail, J., J. Zana, and B. Pénzes. 2008. The role of plant characteristics in the resistance of white cabbage to onion thrips: preliminary results. Acta Phytopathol. Entomol. Hung 43: 267-275.

Kirk, W. D. 1984. Ecologically selective coloured traps. Ecol. Entomol. 9: 35-41.

Kogan, M., and E. F. Ortman. 1978. Antixenosis: a new term proposed to define Painter's "nonpreference" modality of resistance. Bull. Entomol. Soc. Am. 24: 175-176.

Larentzaki, E., A. M. Shelton, and J. Plate. 2008. Effect of kaolin particle film on Thrips tabaci (Thysanoptera: Thripidae), oviposition, feeding and development on onions: a lab and field case study. Crop Prot. 27: 727-734.

Lintner, J. A. 1892. A thrips attack on cabbage. Country Gentleman 57: 809 .

Lu, F. M. 1990. Color preference and using silver mulches to control the onion thrips, Thrips tabaci Lindeman. Chin. J. Entomol. 10: 337-342.

Matteson, N. A., I. Terry, A. Ascoli-Christensen, and C. Gilbert. 1992. Spectral efficiency of the western flower thrips, Frankliniella occidentalis. J. Insect Physiol. 38: 453459.

Mazza, C. A., M. M. Izaguirre, J. Zavala, A. L. Scopel, and C. L. Ballaré. 2002. Insect perception of ambient ultraviolet-B radiation. Ecol. Lett. 5: 722-726.

Mazza, C. A., M. M. Izaguirre, J. Curiale, and C. L. Ballaré. 2010. A look into the invisible: ultraviolet-B sensitivity in an insect (Caliothrips phaseoli) revealed through a behavioural action spectrum. Proc. R. Soc. B 277: 367-373.

Menzel, R. 1979. Spectral sensitivity and color vision in invertebrates, pp. 503-580. In H. Autrum (ed.), Handbook of Sensory Physiology, p. 729. Springer, Berlin, Germany.

Murai, T. 2000. Effect of temperature on development and reproduction of the onion thrips, Thrips tabaci Lindeman (Thysanoptera: Thripidae), on pollen and honey solution. Appl. Entomol. Zool. 35: 499-504.

Natwick, E. T., J. A. Byers, C. C. Chu, M. Lopez, and T. J. Henneberry. 2007. Early detection and mass trapping of Frankliniella occidentalis and Thrips tabaci in vegetable crops. Southwest. Entomol. 32: 229-238. 
North, R. C., and A. M. Shelton. 1986. Colonization and intraplant distribution of Thrips tabaci (Thysanoptera: Thripidae) on cabbage. J. Econ. Entomol. 79: 219-223.

Ocean Optics Inc. 2003. OOIBase 32 spectrometer operating software: operating instructions. Dunedin, FL.

Painter, R. H. 1951. Insect resistance in crop plants, p. 520. The Macmillan Company, New York, NY.

Shelton, A. M., W. T. Wilsey, and M. A. Schmaedick. 1998. Management of onion thrips (Thysanoptera: Thripidae) on cabbage by using plant resistance and insecticides. J. Econ. Entomol. 91: 329-333.

Shelton, A. M., J. Plate, and M. Chen. 2008. Advances in control of onion thrips (Thysanoptera: Thripidae) in cabbage. J. Econ. Entomol. 101: 438-443.

Shevchenko, V. B., and N. A. Popov. 1989. Biology of Thrips tabaci (Thysanoptera, Thripidae) on greenhouse crops. Acta Entomol. Fenn. 53: 47-52.

Sirrine, F. A., and V. H. Lowe. 1894. Insects affecting late cabbage. N.Y. Agric. Exp. Sta. Bull. 83: 657-684.

Stoddard, M. C., and R. O. Prum. 2008. Evolution of avian plumage color in a tetrahedral color space: a phylogenetic analysis of New World buntings. Am. Nat. 171: 755-776.

Stoner, K. A., and A. M. Shelton. 1988a. Role of nonpreference in the resistance of cabbage varieties to the onion thrips (Thysanoptera: Thripidae). J. Econ. Entomol. 81: 1062-1067.

Stoner, K. A., and A. M. Shelton. 1988b. Influence of variety on abundance and within-plant distribution of onion thrips (Thysanoptera: Thripidae) on cabbage. J. Econ. Entomol. 81: 1190-1195.

Szénási, A., G. Jenser, and J. Zana. 2001. Investigation on the colour preference of Thrips tabaci Lindeman (Thysanoptera: Thripidae). Acta Phytopathol. Entomol. Hung 36: 207-211.

Terry, L. I. 1997. Host selection, communication and reproductive behavior, pp. 65-118. In T. Lewis (ed.), Thrips As Crop Pests, p. 740. CAB International, Oxon, United Kingdom.

Teulon, D.A.J., and D. R. Penman. 1992. Colour preferences of New Zealand thrips (Terebrantia: Thysanoptera). N.Z. Entomol. 15: 8-13.

Trdan, S. 1999. Colour preference of some economically important Thysanoptera species, pp. 493-498. In Proceedings, Symposium: 4th Slovenian Conference on Plant Protection, 3-4 March 1999, Portorož, Slovenia. Plant Protection Society of Slovenia, Ljubljana, SI.

van Rijn, P.C.J., C. Mollema, and G. M. Steenhuis-Broers. 1995. Comparative life history studies of Frankliniella occidentalis and Thrips tabaci (Thysanoptera: Thripidae) on cucumber. Bull. Entomol. Res. 85: 285-297.

Vernon, R. S., and D. R. Gillespie. 1990. Spectral responsiveness of Frankliniella occidentalis (Thysanoptera: Thripidae) determined by trap catches in greenhouses. Environ. Entomol. 19: 1229-1241.

Received 16 May 2013; accepted 30 September 2013. 